\title{
Segredos nossos de cada dia
}

\author{
VERA Drake (O segredo de Vera \\ Drake).
}

Direção: Mike Leigh.

Inglaterra/França/Nova Zelândia, 2004. (125 min), son., leg., color., $16 \mathrm{~mm}$.

O segredo de Vera Drake, filme de 2004 do diretoringlês Mike Leigh, se passa, prova velmente, nos inícios da década de 1950 em uma Inglaterra silenciosamente ocupada em se refazer das agruras da II Guerra. O a mbiente onde se passa o filme - evidenciado no espaço exíguo da casa na economia dos afetos entre os membros da família, na contenção das emoções - pode ser lido na clave de uma crônica minuciosa da vida de escassez material e emocional daqueles personagens sorumbáticos que se falam aos cochichos, como se a existência fosse frágil demais para ser exposta a cada dia.

A a triz Imelda Staunton, protagonista do filme, enca ma esse estereótipo de mulher (inglesa) de classe trabalhadora em uma Londres empobrecida do segundo pós-guerra. Com seu ca belo grisalho, seu chapéu barato, seus sapatos pesados, suas roupas suadas e um timbre de voz quase infantil, ela é plena de solicitude, de humildade, de subserviência. Sobe e desce escadas, limpa objetos, lustra móveis e utensílios tomando cuidados infindáveis com um simples pormenor, sempre calada, obediente, mas com uma energia inesgotável, a fim de distribuir sua a tenção. Não poraca so, uma representação do que se imagina uma mulher trabalhadora daquele período, e que fazsentido considerando a trajetória de Mike Leigh, um dos expoentes do realismo social inglês, junto com Ken Loach e outros. Este talvez seja um dos aspectos que ma is incomode no filme: a construção de personagens excessivamente 'típicos', partic ula rmente a personagem Vera, mas também sua cunhada e sua filha, o que é desnecessário diante da magnitude do tema e da forma como é tratado. Pode-se pensarno lugar-comum como asclasses populares no cinema, em grande parte, costumam ser retratadas, sem maiores a mbigüidades, densidades, sutilezas, como pessoas de came e osso, a lutar pelo dia-a-dia.
Certa infantilização e ingenuida de são, portanto, tra ç os fortes na c a rac teriza ção de Vera, mesmo ela sendo a protagonista desse importante segredo que faz parte do repertório do agency da história das mulheres, como nos mostram as historiadoras que se debruçaram sobre o tema, em diferentes contextos. Ou seja, a inda que realizadas de forma secreta, mas nem sempre percebida como "ilegal", as práticas de aborto e infanticídio têm sido, historicamente, parte fundamental da capacidade de agenciamento no que tange a suas vidas sexual e reprodutiva, formas veladas, nem sempre objetivas ou conscientes, de resistência aos padrões rígidos exigidos das mulheres casadas, solteiras, viúvas, divorciadas. Por outro lado, o fa to de considerar 'natural' (ou seja, habitual, costumeiro) o que faz - desde atender os necessitados a té ajudar as moças a se livrarem do 'mal' representado por uma gravidez indesejada - mostra o quanto a dimensão da experiência de classe carrega consigo, inevitavelmente, experiências cultura is específicas, estas, por sua vez, fortemente generificadas, como no caso da sexualidade feminina da qual o assim chamado "aborto" é parte constitutiva.

Vera trabalha como faxineira, embala lâmpadas numa fábrica e cuida do marido e do casal de filhos, uma jornada mais que dupla. Mesmo assim, sempre tem tempo para quem precise dela, seja conhecido ou não. Podemos ver Vera, sob a lente de Mike Leigh, até mesmo como uma mulher moralista, no sentido de cumpridora de deveres, observadora de normas de conduta, envergonhada (valores mora is), uma verda deira "cuida dora" de outrem, sob retudo, de velhos/as, filhos e filhas, doentes, solitários e, finalmente, de outras mulheres quando estas estão precisando de ajuda. Não sa bemos se Vera foi, ela mesma, protagonista de um "aborto" vamos usar esta palavra desconfortavelmente, aqui, seguindo a ótic a do filme - mas poderia ter sido, sim, já que sabemos que muitas mulheres, justa mente por serem 'mães minima mente boas', ou seja, por valorizarem a infância e não desejarem ter um filho de qualquer jeito, recorreram, em algum momento de suas vidas, a essa prática. Vera é uma 'boa mãe': devotada à família, pretende casar a filha e arquiteta estratégias para promover seu namoro tão logo descobre um moço solteiro como vizinho de seu prédio, convidando-o para jantar em família e 
acolhendo-0, após um relato triste de sua participação na guerra.

Após várias cenas compassadas pela presença de chaleiras e de chás, marcas daquele cotidiano bem inglês, nas várias casas que visita para cuidar, vemos Vera repetir quase o mesmo gesto (levar água para ferver), mas ta mbém preparando os instrumentos (doméstic os) para ajudar sempre aquelas "mulheres que estão precisando de a juda" - expressão utiliza da a té a terc eira parte do filme, quando, fina Imente, Vera 'aprende' a daroutro nome para essa ajuda, que seria, segundo a étic a representa da pelo policial, chamada, então, a partir da entrada em cena dos a parelhos estatais, de aborto.

Essa cena é particularmente importante, pois mostra um processo de nominação e/ou c lassificação de uma prática costumeira, cujos sentidos destoam daquilo que veio a chamar-se "aborto", e que foi partilhada por mulheres não apenas naquele contexto inglês/europeu, pósguerra, mas em muitos outros momentos e em outras sociedades. Estudos de Joana Pedro ${ }^{1}$ e equipe e de Flá via Motta, ${ }^{2}$ por exemplo, feitos no sul do Brasil, mostram que até meados do século XX muitas mulheres, diante de uma gravidez indesejada, recorrera $m$ a procedimentos similares no sentido de "fazer o sangue descer" ou "eliminar coágulos ou bolinhas de sangue", sem acreditar que, com isso, estariam "interrompendo vidas", para utilizar uma expressão tão cara aos chamados movimentos "pró-vida" dos tempos contemporâneos e consoante à posição da Igreja Católica Apostólica Romana diante desse tema. Há, a inda os estudos etnográfic os que apontam para a prática do infanticídio em diversos grupos humanos, seja como forma de controle demográfico, seja em função de razões propriamente simbólicas, como no caso de gêmeos.

No caso do Ocidente, a história da condenação do aborto corre em paralelo com o desenvolvimento da noção de infância e com a antecipação da noção de pessoa para o período gestacional. Além disso, muitas pessoas, muito embora condenem a prática do aborto em abstrato, diante de situações concretas de um cotidiano difícil, econômica ou subjetivamente, recorrem a essa prática, dentro de uma lógica que oscila entre o nível ma is genérico da regra e o nível da prática, esta muito ma is complexa do que aquela, como mostra o estudo de Ondina Leal, entre outros. ${ }^{3}$ De igual maneira, as lutas sela "lega lização" dessa prática - a pesarda proibição recorrente - é mais recente, e bastante heterogênea, conforme os diferentes contextos naciona is. ${ }^{4}$

No caso da Inglaterra, o aborto foi regula riza do em 1967 - depois da condenação de Vera e das outras mulheres que ela encontra na prisão. Na concepção da protagonista, rea lizar resse serviço era uma ra mific açã o natural do a to de estendera carida de a quem necessita dela. Ela não aceita dinheiro, pois atua dentro de uma lógica que podeńa mos chamarde lógica da reciprocidade, lógica essa que permeia, até hoje, grande parte dos assuntos de mulheres, partic ula mente os partos, quand o são rea liza dos fora dospadrões medic a liza dose medic a lizantes modernos. Em contextos populares e rura is mulheres socorrem outras mulheres porque, imbuídas de sentimentos religiosos, entendem que não podem deixá-las sós nessa s oc a siões. Soraya Fleicher mostra, em sua etnografia das mulheres que atendem partos do Pará, ${ }^{5}$ o quanto essa lógica está presente, ainda hoje, nas práticas relacionados ao darà luz, e tal observação faz eco com vários outros estudos que tra tam do tema do parto e, certamente, das interrupções de gestações que andam a o lado desse affaire des femmes. ${ }^{6}$

Vera não vive em uma aldeia longínqua e distante dos grandes centros, mas no epic entro da sociedade burguesa, em franca transformação: faz parte de um contexto fa miliar 'popular' da classe trabalhadora inglesa tão celebrada pelos cineastas da escola de Mike Leigh, que a apresenta, aqui, ta mbém com suas pretensões de mobilidade social, de internalização dos valores da sociedade de consumo e - junto com isso - da moral burguesa que a a companha. No filme, nesse sentido, há cenas bastante signific a tiva s como, por exemplo, aquelas que mostram o filho de Vera - o único da família que precisa de tempo e explicações para 'perdoar' a mãe -, a cunhada de Vera que atormenta seu marido com seus desejos insaciáveis de consumo e declarada vergonha pelos traços populares de seu matrimônio - e, ainda, a 'amiga' de Vera, que the revende, a preços que diz "especiais", alimentos de difícil aquisição naquele contexto de escassez do recente pós-guerra, exatamente nos mesmos encontros em que the repassa, sorrateiramente, endereços e horários das mulheres "em a puros". É ela que cuida da agenda (secreta) de Vera e descobre as meninas em apuros.

Essa sua muy amiga age discreta e rapidamente. Ninguém sabe o nome de Vera, que nunca recebeu um tostã o pela sua ajuda, e ela tampouco sabe o nome de ninguém. Humilde, 
calada e subserviente, Vera Drake continua a 'ajudar as mulheres' até que uma das suas 'pacientes' é obrigada a intemar-se após graves seqüelas do aborto feito por Vera, e o sigilo é quebrado. Pode-se considerar, a qui, uma crític a à sociedade inglesa capitalista, afinal ela trabalha de graça e não recebe nada!

No filme, que se passa por volta de 1950, vemos trabalhadores apertados em espaços exíguos, mas há separações: é uma vida privada que, aos poucos, se publiciza e permite pensar na entrada da mulher na esfera pública, a inda que em trabalhos afeitos a o campo do privado.

O método empregado pela protagonista de inundar o útero com água e sabão, é um desses horrores que respondem pelos óbitos asso cia dos a abortos c la ndestinos e certamente o diretor não usa seu filme para fazer a defesa dessa prática. O assunto de Vera Drake extrapola esta questã o: mostrar, quem sabe, uma prática ainda presente na vida de mulheres pobres. 0 tema, na verdade, é o vácuo - entre o que se faz e o que se pode admitir, entre a lei e a vida e também entre a inocência e a culpa.

Quando a polícia bate à porta da casa de Vera, na noite do noiva do de sua filha, ela desaba sobre o peso da vergonha de seusfamiliares (que não sabiam até ali do segredo da personagem). Seu ethos moral desaba pela desilusão de saber que o que ela julgava serbondade quase resultou num assassinato. Interessante observar que, diante da cena familiarinterrompida pela busca da ré e, mais a inda, diante de seu estarrecimento sincero, Vera conta com uma compreensão silenciosa dos doisagentes da polícia. Ainda em seu quarto, o chefe dospolic ia is dá c la rasmostras de compreender sua lógica, e assim segue a té mesmo quando a acompanha ao tribuna superior. A companhia solidária do marido que espera e não pergunta parece evidenciar o ruir daquele mundo tão estreito feito de silêncios. A policial que a leva à cela, de onde não sa irá por não tera quantia necessária para pagara fiança, também demonstra compartilhar dessa lógica. Ela parece compreenderas razões das mulheres que 'abortam', e de Vera que asajuda, mostrando aí, mais do que o pertencimento de classe - que é marcado por experiências cultura is compartilhadas, como nos ensinam os historiadores ingleses -, ta mbém uma identidade de gênero.

Aliás, o filme exporá muito bem as fraturas intemas a essa s experiências femininas, cindidas fortemente pela fronteira de classe: aqui, Mike Leigh parece fazer eco aos clamores dos movimentos feministas, que chamam a a tenção para as mortes matemas decorrentes de abortos malfeitos na clandestinidade pelas mulheres pobres ou amedrontadas, e de outros feitos por aquelas que, igualmente alvo da voracidade e brutalidade masculina, conseguem pagar os serviç os p rofissiona is e rea liza m os proc ed imentos em c línic a s bem equipa das, sob a s vista s grossa s do Estado e contando com a hipocrisia dos moralistas de plantão.

Interessante que, como costuma acontecer nos debates sobre o aborto, as penas e culpas costumam cair sobre as mulheres que 'ajudam', as que dominam os mistérios e os misteres do "aborto" e as que recorrem a ele como forma de evitar a "matemidade". Pouco ou nada se fala dos homens, cúmplices ou algozes do ato que pode levar àquela gravidez. Nesse sentido, o desfile de mulheresajudadasporVera serve como exemplo para mostrarasrazõesque levam a essa escolha, e o sofrimento pelo qual a grande maioria delas passa quando escolhe recorrer a essa prática para evitar uma matemidade sem prazer nem parceria. Convém destacar a cena em que aparecem personagens em geral ausentes do debate público acerca do tema como, por exemplo, no detalhamento do verda deiro estupro do qual é a lvo a filha "do juiz", cheia de recursos materiais, mas desprovida de rec ursos simbólic os para detera violência de seu namorado.

Presa e privada de sua missão de mãe, dona-de-casa e mulher, a protagonista a tra vessa uma morte simbólica da qual prova velmente só sa irá quando vier outra, a última. E, privados de Vera, os que a cercam perdem o único elo palpável entre o mundo duro no qual vivem e a quele outro, melhor, a o qual esperam chegar, já que não há quem ocupe o vazio deixado por sua partida, referência ao papel catalisador e aglutinador que as mulheres, naquele contexto, também, pareciam ter no que tange à organiza ção familiar. A última cena do filme é de uma secura impressionante: to dos esperam em silênc io um retomo que não se sabe se acontecerá.

No momento em que, no Brasil, particularmente, a polêmica em tomo do aborto legal se reacende (desengavetamento de projetos relativos ao tema pelo Congresso, visita e recomendações de Bento XVI, declarações do Govemo Federal, fortalecimento dosmovimentos pró-vida e pró-descriminaliza ção do aborto) revelando sua dimensão de 'campo de guerra', filmes c omo o de Mike Leigh são imprescindíveis, juntamente com outros que tratam fic cionalmente do tema, como Um assunto de mulheres, ${ }^{7} 0$ estadunidense 0 preço de uma escolha ${ }^{8}$ (este uma comparação entre trêsépocas, trêscontex- 
tos e três decisões ou escolhas), sem falar do recente e premiado documentánio da antropóloga Débora Diniz (História de uma vida severina). ${ }^{9}$

Atual e contund ente, o filme permite evocar um panfleto, recentemente distribuído nas ruas de Brasília, em um a to público, onde se lê:

Todo mundo tem um história para contar, conhece alguém de sua família, escola ou comunidade que engravidou fora da hora, apesar de usar contraconceptivo, que sofreu um estupro e, infelizmente, além de toda a violência, engra vidou. Ou então a quela a miga cujo namorado ou marido não admite usa preservativo. Já ouviu falar também de mulheres que sofreram abortos natura is. 0 Aborto faz parte da vida e da saúde das mulheres. ${ }^{10}$

Lúcido e instigante, O segredo de Vera Drake encoraja as pessoas a se libera rem de suas próprias referências e, nesse sentido, assistir ao filme é um ótimo convite à retira da desse sonoro silêncio do rol dos assuntos que devem ser discutid os por todos e todas, sem preconceitos.

\section{Notas}

1 PEDRO, 2003a.

2 MOTTA, 1998.

${ }^{3}$ Ondina Fachel LEAL e Bemardo LEWGOY, 1995, p. 57 76.

${ }^{4}$ PEDRO, 2003b.

${ }^{5}$ FLEICHER, 2007

${ }^{6} \mathrm{~A}$ propósito, Un affaire de femmes (Um assunto de mulheres) é o título do filme de Claude Chabrol, protagonizado por Isabelle Hupert, e que trata desse tema, também durante a II Guema Mundial na França (UN AFFAIRE... 1994).

7 UN AFFAIRE..., 1994

${ }^{8}$ IF THESE WALLS COULD TALK, 1996

9 HISTÓ RIA..., 2005

${ }^{10}$ CHEGA DE SILÊNCIO E HIPOC RISIA, 2007.

\section{Referências bibliográficas}

CHEGA DE SILÊNCIO E HIPOCRISIA. O aborto seguro e legal é direito dasmulheres. Brasilia,
2007. Panfleto assinado pela Secretaria das mulheres da CUTe pela Marcha Mundial das Mulheres.

FLEICHER, Soraya. Parteiras, buchudas e aperreios: uma etnografia das práticas obstétricas de Melgaço/Pará. 2007. Tese (Doutorado em Antropologia Social) Universidade Federal do Rio Grande do Sul, Porto Alegre.

LEAL, Ondina Fachel; LEWGOY, Bemardo. Pessoa, aborto e contracepção: corpo e signific ado. Porto Alegre: Editora da UFRGS, 1995.

MOTTA, Flá via. Sonoro silêncio: por uma história social do aborto. São Paulo: Fundação Carlos Chagas, 1998. Relatório de pesquisa. Mimeo.

PEDRO, J oa na (Org.). Prátic as proibidas: prátic as costumeiras de aborto e infanticídio no século XX. Florianópolis: Cidade Futura, 2003a.

PEDRO, Joana. "A repercussão das disputas legislativas: a legislação sobre o aborto e a imprensa". In: PEDRO, Joana (Org.). Práticas proibidas: práticas costumeiras de aborto e infanticídio no século XX. Florianópolis: Cidade Futura, 2003b. p. 169-187.

\section{Referências fílmicas}

HISTÓ RIA de uma vida severina. Direção: Débora Diniz e Elia ne Brum. Brasil: Anis, 2005. 1 filme, son., color.

IF THESE WALLS COULD TALK (O preço de uma escolha). Direção: Chere Nancy Savoca. EUA, 1996. 1 filme, son., leg., color., $16 \mathrm{~mm}$.

UNE AFFAIRE des femmes (Um assunto de mulheres). Direção: Claude Chabrol. França, 1994. 1 filme, son., leg., color., $16 \mathrm{~mm}$.

Carmen Susana Tomquist Universidade do Estado de Santa Catarina

Maria Teresa Santos Cunha Universidade do Esta do de Santa Catarina 